\title{
Corrigendum
}

\section{Impact of food supplementation on weight loss in randomised controlled dietary trials: a systematic review and meta-analysis - CORRIGENDUM}

Cinthya Wibisono, Yasmine Probst, Elizabeth Neale and Linda Tapsell

(First published online 29 December 2016)

doi:10.1017/S0007114516000337, Published by Cambridge University Press.

\section{Original text and correction}

Original text in Fig. 1: $\mathbf{n}=\mathbf{9}$ under 'Food v. no food' $\mathbf{n}=\mathbf{7}$ under 'Food v. food'.

Correct text: $\mathbf{n}=\mathbf{1 2}$ under 'Food v. no food' and $\mathbf{n}=\mathbf{4}$ under 'Food v. food'.

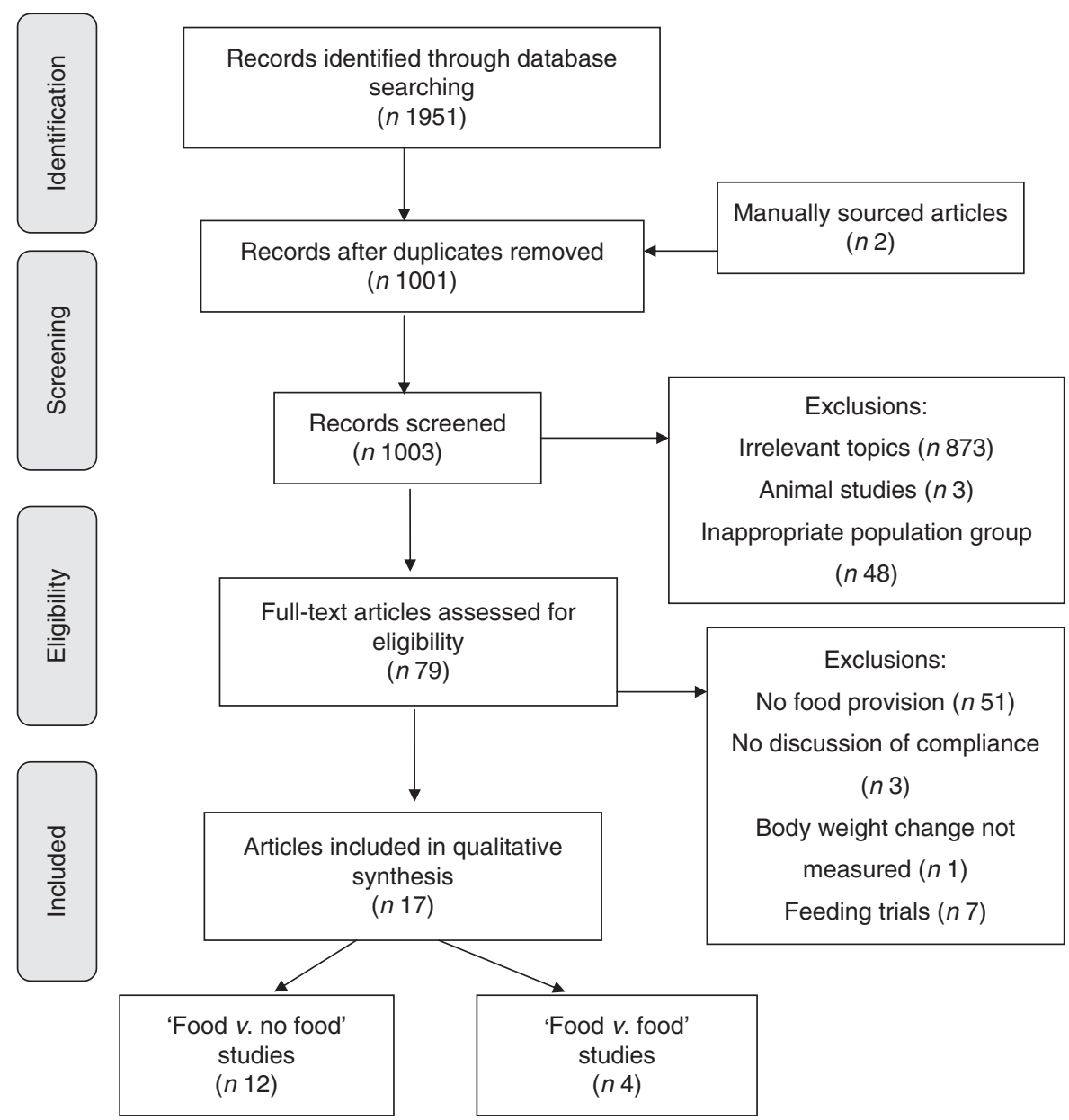

Fig. 1. PRISMA Flow diagram of study selection. 